\title{
Cytopathic bovine viral diarrhea viruses (BVDV): emerging pestiviruses doomed to extinction
}

\author{
Ernst Peterhans*, Claudia Bachofen, Hanspeter Stalder, Matthias Schweizer* \\ Institute of Veterinary Virology, University of Bern, Länggass-Strasse 122, PO Box 8466, CH-3001 Bern, \\ Switzerland
}

(Received 11 December 2009; accepted 2 March 2010)

\begin{abstract}
Bovine viral diarrhea virus (BVDV), a Flaviviridae pestivirus, is arguably one of the most widespread cattle pathogens worldwide. Each of its two genotypes has two biotypes, non-cytopathic (ncp) and cytopathic (cp). Only the ncp biotype of BVDV may establish persistent infection in the fetus when infecting a dam early in gestation, a time point which predates maturity of the adaptive immune system. Such fetuses may develop and be born healthy but remain infected for life. Due to this early initiation of fetal infection and to the expression of interferon antagonistic proteins, persistently infected (PI) animals remain immunotolerant to the infecting viral strain. Although only accounting for some $1 \%$ of all animals in regions where BVDV is endemic, PI animals ensure the viral persistence in the host population. These animals may, however, develop the fatal mucosal disease, which is characterized by widespread lesions in the gastrointestinal tract. Cp BVD virus, in addition to the persisting ncp biotype, can be isolated from such animals. The $\mathrm{cp}$ viruses are characterized by unrestrained genome replication, and their emergence from the persisting ncp ones is due to mutations that are unique in each virus analyzed. They include recombinations with host cell mRNA, gene translocations and duplications, and point mutations. Cytopathic BVD viruses fail to establish chains of infection and are unable to cause persistent infection. Hence, these viruses illustrate a case of "viral emergence to extinction" - irrelevant for BVDV evolution, but fatal for the PI host.
\end{abstract}

emerging pestivirus / immune evasion / RNA recombination / persistent infection / virus evolution

\section{Table of contents}

1. Introduction.

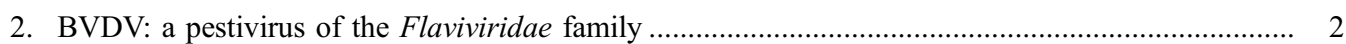

3. Persistent infection with BVDV, the emergence of cp BVDV, and mucosal disease ...................... 5

4. Evolution of BVDV: the role of persistent infection and the emergence of cp biotypes ................. 8

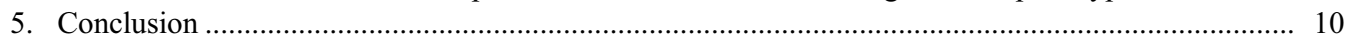

\section{INTRODUCTION}

The Websters New World Dictionary explains the meaning of the verb "emerge" as (i) "to rise from a surrounding fluid," (ii) to come forth into view, to become visible, to become apparent or known, and (iii) to develop or evolve as something new. As regards viruses, the most frequent usage of "emerging" follows the latter explanation; even though, in many cases version (ii) would seem to be more appropriate, considering that emerging viruses may have been present for a long time in geographically remote areas before becoming known by

\footnotetext{
* Corresponding authors: ernst.peterhans@ivv.unibe.ch; matthias.schweizer@ivv.unibe.ch

This is an Open Access article distributed under the terms of the Creative Commons Attribution-Noncommercial License (http://creativecommons.org/licenses/by-nc/3.0/), which permits unrestricted use, distribution, and reproduction in any noncommercial medium, provided the original work is properly cited.
} 


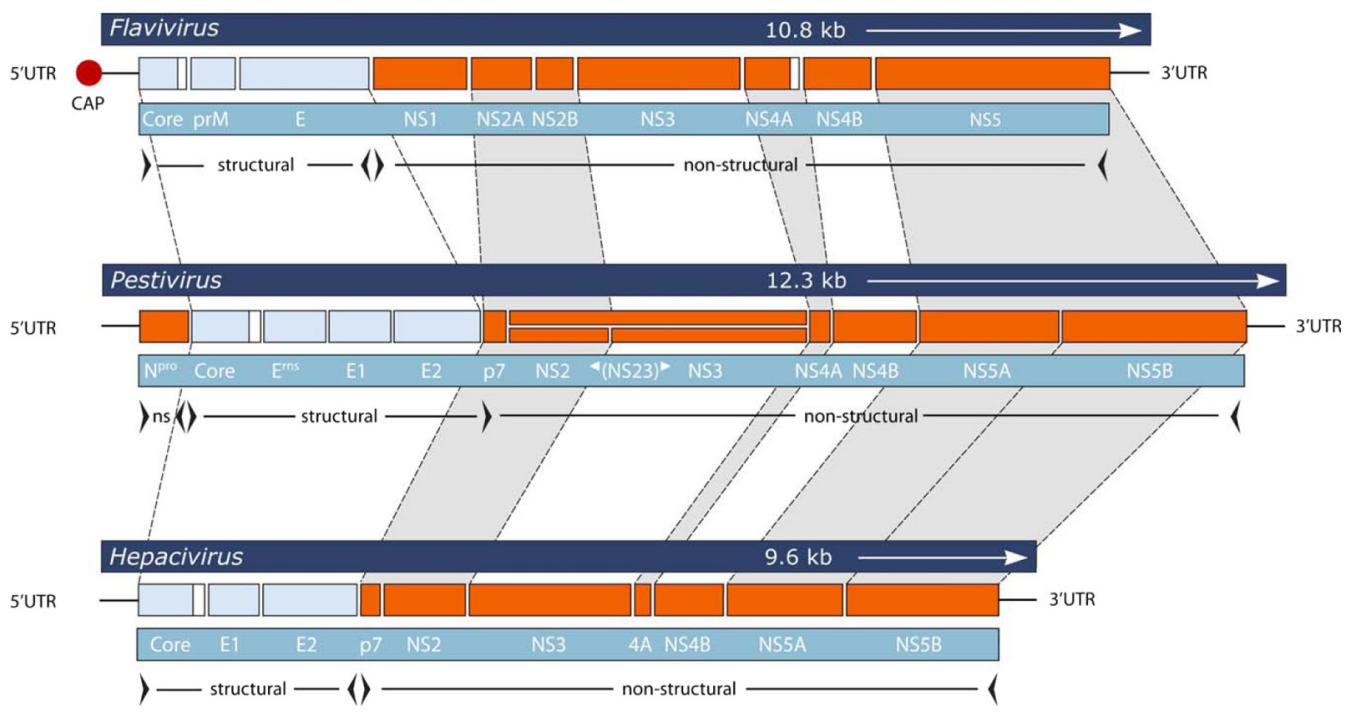

Figure 1. Genome organization of viruses from the genera flavivirus, pestivirus, and hepacivirus within the family Flaviviridae. The length of the viral RNA genomes are illustrated on top of each panel, and homologous regions between the genomes are indicated. Only the RNA of flaviviruses is capped at the 5 -end. The processing of the polyprotein into the individual structural and nonstructural proteins is indicated below. All the core proteins and the NS4A of flaviviruses are further processed at their C-terms (white boxes). For cytopathic pestiviruses, enhanced expression of NS3 is observed, whereas the uncleaved form, NS2-3, predominates in non-cytopathic pestiviruses. ns, non-structural; UTR, untranslated region. (A color version of this figure is available at www.vetres.org.)

infection of humans or domestic animals [22, $40,66,88]$. In this context, labeling bovine viral diarrhea virus (BVDV) as "emerging" may seem to be out of place for a number of reasons. Firstly, this virus is by no means new, the virus having first been described in 1946 [72], and with over 2500 citations listed in PubMed. Secondly, BVDV may well be the most widespread virus in bovines, being present in cattle populations all over the world [34, 37]. However, what justifies inclusion of this virus in this list is the emergence of an altered biotype that results in a spectacular and invariably lethal disease referred to as "mucosal disease".

\section{BVDV: A PESTIVIRUS OF THE FLAVIVIRIDAE FAMILY}

Pestiviruses are a genus of the family Flaviviridae, whose name is derived from the yellow fever virus (from flavus, the skin color of humans suffering from jaundice). Yellow fever virus is the type species of the genus flavivirus. Other medically important representatives of this genus include tick-borne encephalitis virus and Japanese encephalitis virus [54]. The best known representative of the genus hepacivirus is hepatitis $\mathrm{C}$ virus which infects some 120-170 million humans worldwide [2, 84] and is a leading cause of liver cirrhosis and hepatocellular carcinoma [21]. The Flaviviridae are similar in their genetic organization and basic molecular biology (Fig. 1). The genes of the structural proteins are located at the $5^{\prime}$ end of the approximately $10-15 \mathrm{~kb}$ positive single strand RNA genomes, followed in the $3^{\prime}$ direction by the genes encoding the nonstructural proteins. Translation of the genome is started by cap-independent, IRES (internal ribosome entry site)-mediated binding to ribosomes (pestivirus or hepacivirus) or by cap-dependent 


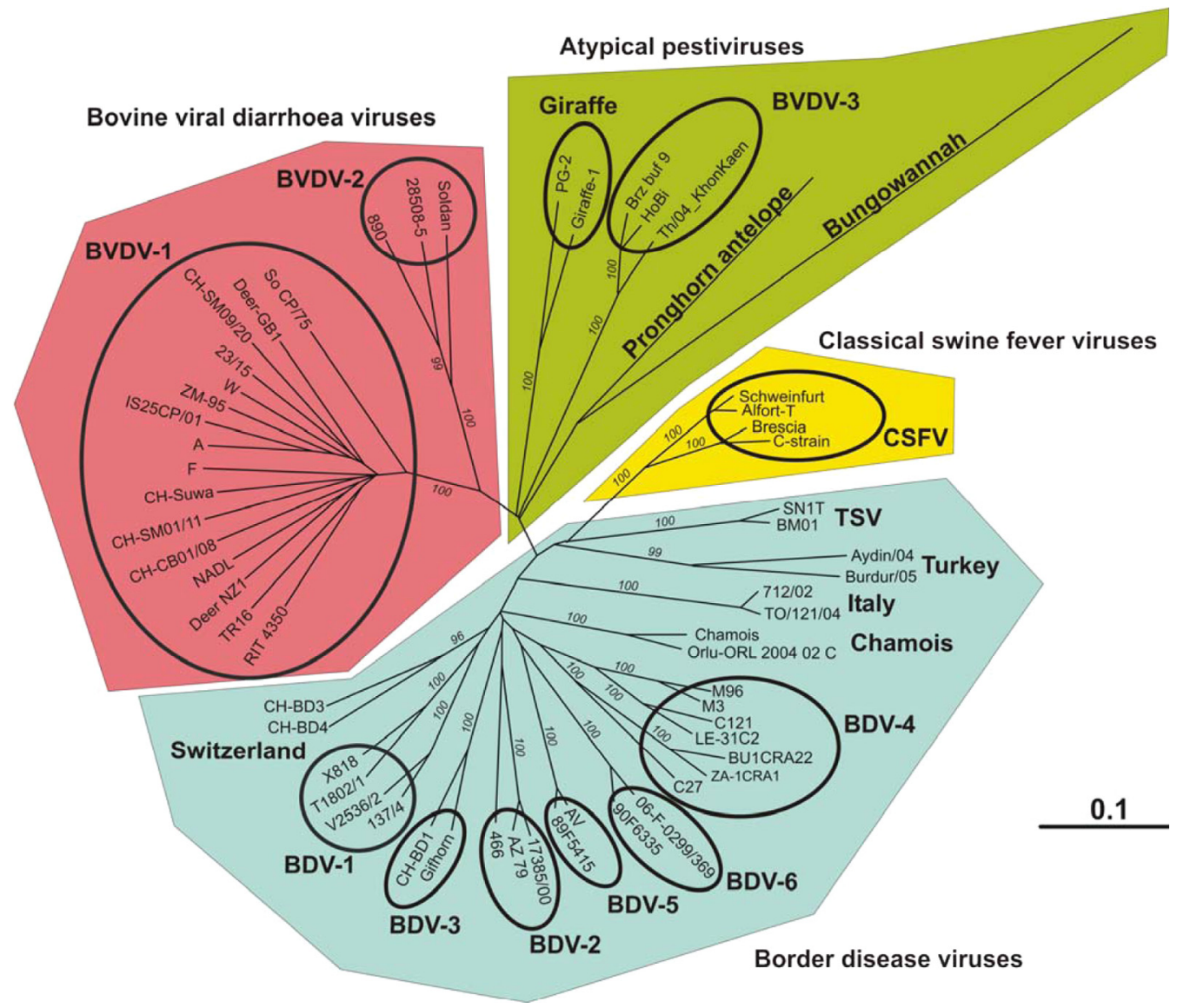

Figure 2. Phylogenetic analysis and classification of pestiviruses based on $\mathrm{N}^{\text {pro: }}$ : The phylogenetic tree that represents the genetic relationship of pestivirus strains was constructed from the complete $\mathrm{N}^{\text {pro }}$ coding sequences except for the two strains Aydin/04 (EU930014) and Burdur/05 (EU930015). However, since constructing the tree with all sequences shortened to 420 nucleotides did not change the basic structure of the tree (data not shown), we included these strains in the analysis. Sequences were obtained from GenBank and the sequences of the Swiss BDV strains CH-BD3 (GU244490) and CH-BD4 (GU244489) were described by C. Reichert ${ }^{1}$. The analysis was computed using the programs included in the GCG software package as PILEUP for the multiple sequence alignment and PAUP for calculating the distances by the Kimura 2-parameter method and constructing the tree according to the neighbor-joining method. Branch numbers (italics) indicate the percentage of 1000 bootstrap replicates. Only bootstrap values over 95 are shown. Branch lengths are proportional to genetic distances, and the bar shown indicates 0.1 substitutions per site. The classification of the various pestiviruses was composed according to $[23,71,94]$. Virus strains within the "BVDV-3" group were named according to [56, 57], but they had previously also been labeled as "unclassified" [90] or "atypical" [55]. Virus strains within the chamois group in this paper were sometimes assigned to BDV-4 $[3,61,71,78,93,99]$, whereas the Tunisian isolates SN1T and BM01 were recently labeled as TSV (Tunisian sheep virus, [57]). (A color version of this figure is available at www.vetres.org.)

\footnotetext{
${ }^{1}$ Reichert C., Infektion von Kälbern, Schafen und Ziegen mit Border-Disease-Virus, Veterinary Doctoral thesis of the Vetsuisse Faculty, University of Zurich, Switzerland, 2009.
} 


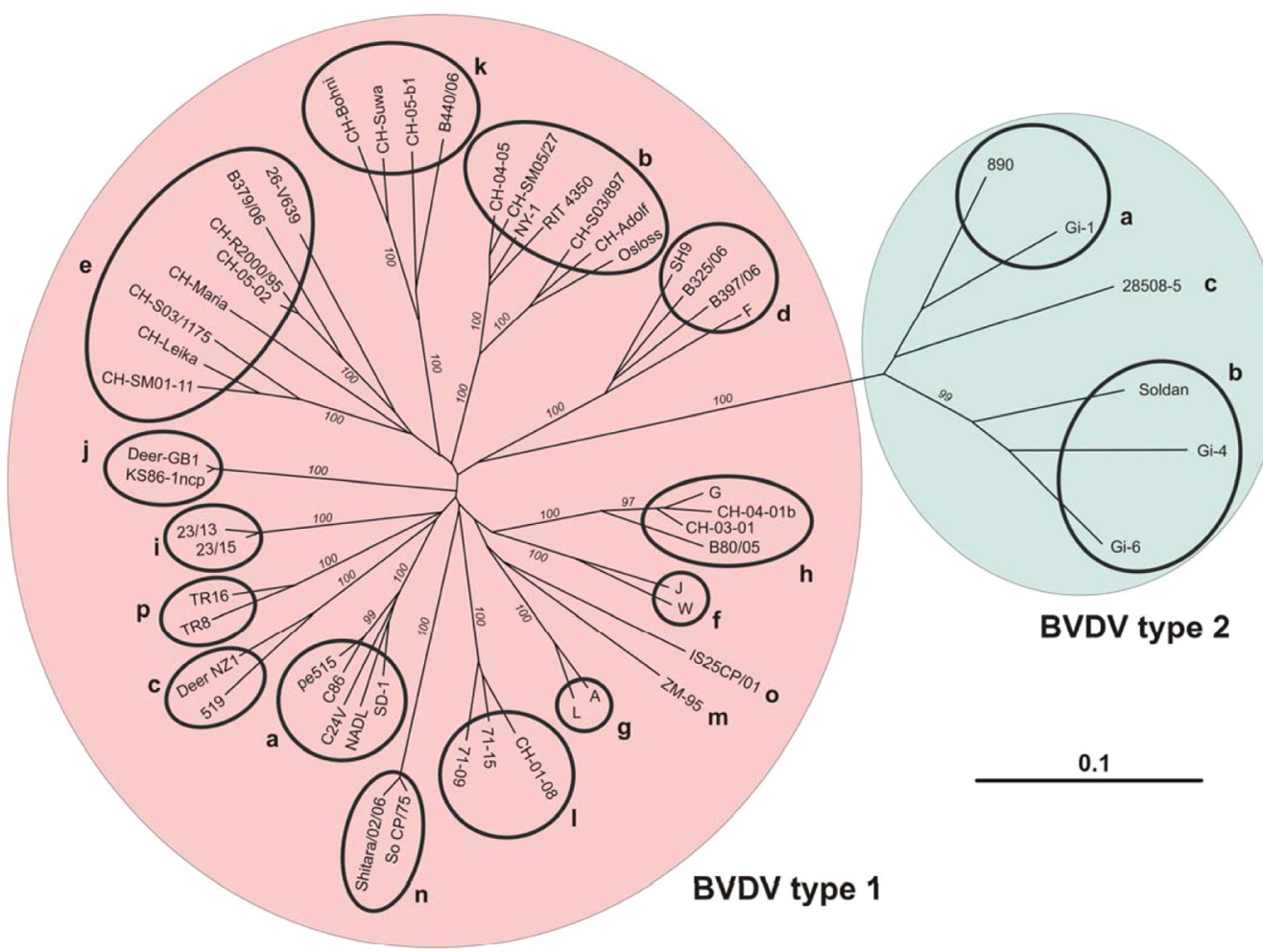

Figure 3. Phylogenetic analysis and classification of BVDV based on $\mathrm{N}^{\text {pro }}$ : The phylogenetic tree that represents the genetic relationship of BVDV strains was constructed from 349 nucleotides of the $\mathrm{N}^{\text {pro }}$ coding sequences. The genetic analysis was calculated and the figure prepared as described for Figure 2. The sub-genotype BVDV type-11 was assigned according to [36, 39]. The strains So CP/75 and TR8/TR16, which were also labeled as BVDV-11 by [5, 102] and [104], were renamed as BVDV type-1n and -1p, respectively. BVDV sub-genotypes $\mathrm{m}, \mathrm{n}$, and o were named as in [70]. All other groups were assigned as suggested by $[97,98]$. (A color version of this figure is available at www.vetres.org.)

initiation by ribosomal scanning (flavivirus). The genomes contain a single open reading frame which result in proteins of 3000 to 4000 amino acids. Cleavage of the polyprotein into the mature individual proteins is by virally and host-encoded proteases (for a review, see [54]).

Pestiviruses infect even-toed animals (order Artiodactyla). These hosts are quite diverse and, in addition to domestic animals such as cattle, sheep, and old and new world camelids, include feral animals such as antelopes and deer (Fig. 2). Since the search for pestiviruses in feral animals is not a research priority of granting agencies, it seems likely that the spectrum of pestiviruses may be considerably wider than those known to date, and thus other strains will be found in the near future. An example illustrating this point is the recently discovered Bungowannah virus. Although this virus was detected in pigs suffering from myocarditis, its origin is unknown and may well be found in wildlife [24, 43]. It remains unknown whether these emerging strains cause various diseases in their host animals or whether they are indirectly involved due to the immunosuppressive effect of pestiviruses [12, 20, 76, 79]. Notably, a number of BVDV strains were identified as being responsible for contamination in cell cultures, e.g., strain HoBi [83] or $\mathrm{CH}-\mathrm{KaHo} /$ cont [90], both found to be similar 
to virus strains isolated in Brazil or Thailand [89, 90], or strain PG2 (Fig. 2) which we found in bovine cells prepared in Kenya with local serum [10]. Thus, it would come as no surprise if many laboratories working with cell cultures of ruminants unwittingly propagate pestiviruses (see, e.g., [4, 7, 62, 96], and unpublished observation). The taxonomy of pestiviruses is constantly changing, partly because of the discovery of new pestiviruses, but also because the criteria for the allocation of species status and division in subgroups within a given species (Fig. 3) are not used uniformly [41, 57, 58]. Currently, the pestiviruses include four official species ${ }^{2}$ (Fig. 2), BVDV-1 and -2 , classical swine fever virus (CSFV) and border disease virus (BDV), and one tentative fifth species represented by only two strains, Giraffe-1 (H138) and PG2 [10].

\section{PERSISTENT INFECTION WITH BVDV, THE EMERGENCE OF CP BVDV, AND MUCOSAL DISEASE}

For recent reviews on BVDV, see [54, 77, 82]. Although genetically and antigenically diverse (Fig. 3), BVDV type-1 and BVDV type-2 have in common the existence of two biotypes that are differentiated according to either inducing death in cultured cells (cytopathic biotype, $c p$ ), or failing to induce cell death (non-cytopathic biotype, ncp). However, it is important to note that the cytopathogenicity of a pestivirus does not correlate with its virulence, since most virulent, i.e. disease causing, strains are of the ncp biotype [77]. The two biotypes are closely associated with two fundamentally different forms of infection in cattle either transient or persistent. BVD viruses of the cp biotype emerge from ncp ones exclusively in persistently infected (PI) animals and are invariably associated with a lethal outcome of persistent infection, referred to as mucosal disease (Fig. 4). Some $60 \%$ of animals living in regions where BVDV is endemic and not influenced by control measures are transiently

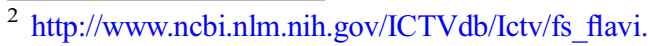
htm\#Genus2
}

infected at some stage of their lives. These animals may suffer from mild diarrhea or respiratory symptoms or else show no signs of infection at all. After seroconversion, the animals are protected from re-infection for life. Persistent infection is initiated in embryos from the second to fourth of the 9.5 months of development. In most cases, virus reaches the embryo when pregnant animals undergo a transient infection, but virus may also be transmitted to the fetus by a pregnant PI dam. Due to the early period of development, the immature immune system of the fetus fails to mount an adaptive immune response to the virus but develops immunotolerance to the infecting viral strain. Only ncp, but not cp, biotypes of BVDV are capable of establishing and maintaining persistent infection. This difference is associated with a different interaction of the two biotypes with the innate immune response against viral infection, which is active from the very beginning of gestation. Interferon (IFN) type-I (also called IFN- $\alpha / \beta$ ) is a key player in the antiviral defense of the innate immune system that is active before the adaptive immune system kicks in with an antigen-specific defense. Ncp BVD viruses fail to induce IFN type-I in various types of cultured cells whereas infection with $\mathrm{cp}$ virus readily triggers IFN generation [75]. The role of the innate immune response became more prominent when it was recognized that the innate immune system may not be as unspecific as originally assumed [100]. It detects elements that are common to one or several classes of infectious agents, referred to as "pathogenassociated molecular patterns" (PAMP) or "danger signals". Such PAMP are recognized by a limited repertoire of germ-line encoded "pattern recognition receptors" (PRR), such as Toll-like receptors (TLR), RIG-I-like receptors (RLR), or NOD-like receptors (NLR) [65]. These PRR are located at the cell surface, in endosomes, or intracellularly, i.e., at sites that are crucial for the early detection of pathogens.

The recognition of pathogens by the innate immune system is a prerequisite for an adaptive immune response to occur. Dendritic cells (DC) in particular have been recognized to play a central role in primary immune responses, and they also initiate and regulate adaptive 


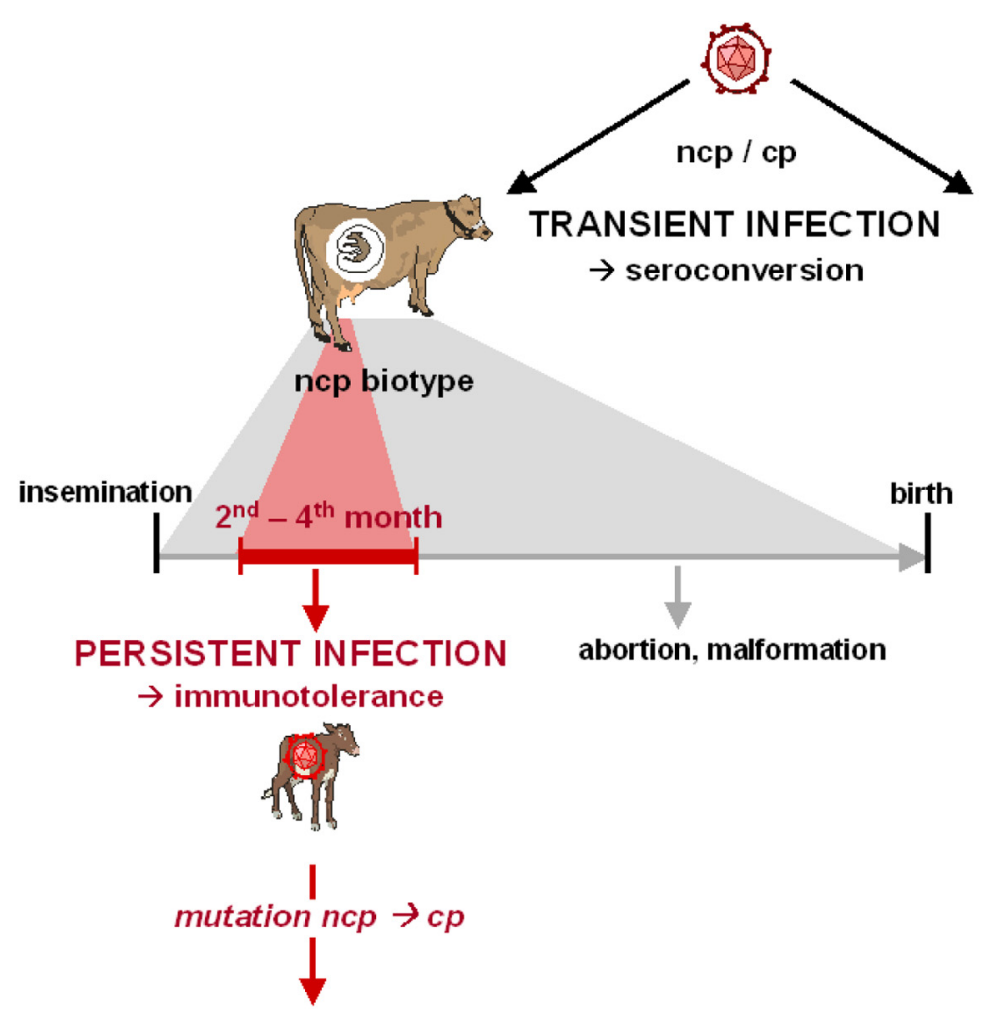

\section{MUCOSAL DISEASE}

Figure 4. Persistent versus transient infections: BVDV causes two types of infection in vivo. Infection of a seronegative animal with BVDV of either biotype leads to a transient (acute) infection that usually causes no or mild clinical symptoms. The virus will be eliminated by the humoral and cellular immune response that will protect the animal from further infections. In contrast, infection with ncp, but not cp, BVDV between the second and fourth month of gestation may lead to persistent infection of the fetus. Infection later in gestation may lead to abortion, malformation, or to the birth of normal, immunocompetent calves. PI calves are immunotolerant to the infecting BVDV strain. These animals are born antibody negative and shed large amounts of virus during their entire lifetime. If the persisting ncp virus mutates into a cp biotype or if the PI animal is superinfected with an antigenically related $\mathrm{cp}$ virus, the PI calf will succumb to the lethal mucosal disease. (A color version of this figure is available at www.vetres.org.)

immunity [52]. DC activated by PAMP produce an array of cytokines, the most prominent one being IFN type-I, linking the innate and adaptive arms of the immune system [11]. This then leads to up-regulation of $\mathrm{MHC}$ expression, presentation of co-stimulatory molecules, efficient activation and cross-priming of T-cells, and stimulation of humoral immunity $[25,51,91]$. In addition, it recently became evident that the cooperation between the innate and adaptive immune system also acts reciprocally, i.e. the adaptive mechanisms have an impact on the innate immune responses [73, 105].

During replication, both biotypes of BVDV express the N-terminal protease $\mathrm{N}^{\text {pro }}$ and the glycoprotein $\mathrm{E}^{\mathrm{rns}}$ (Fig. 1). $\mathrm{N}^{\text {pro }}$ expressed by virus-infected cells targets the transcription factor IRF-3 for proteasomal degradation independently of its protease activity [8, 31, 35, 46], thereby inhibiting IFN generation. In addition, the structural protein $\mathrm{E}^{\mathrm{rns}}$ is also released from infected cells, and by its intrinsic RNase 
activity, it is able to block IFN type-I synthesis induced by extracellular viral ss- and dsRNA even in uninfected cells $[38,60,68]$. However, cp BVD viruses were shown to produce more double-stranded RNA than ncp biotype viruses $[68,103]$. The high concentration of this PAMP signaling viral infection might overwhelm the efficiency of the $\mathrm{N}^{\text {pro }}$ - and $\mathrm{E}^{\mathrm{rns}}$-mediated inhibition of IFN production that, however, suffices in ncp BVD virus-infected cells. Since IFN is an antiviral defense mechanism present from the earliest period of intrauterine development, the evasion of this innate immune response may well contribute to the establishment of persistent infection by BVDV. Indeed, cp BVD virus has been shown to trigger IFN generation in the developing fetus whereas the ncp biotype failed to do so, in line with the capacity of the latter to establish persistent infection [18]. Interestingly, immunologically naïve and virus-free animals infected postnatally produce IFN type-I in response to infection with both biotypes of BVDV [19].

Fetuses infected during the critical period in utero may develop and be born normal. However, they continue to produce and shed large amounts of virus throughout their lives. In such animals, virus can be detected primarily in all types of white blood cells in lymphatic tissues and blood but also in skin and hair roots. In fact, virus can be isolated from epilated hair, and viral RNA can be detected on the skin surface (Bachofen ${ }^{3}$ and Peterhans, in preparation). Clinically, many PI animals may show no, or only mild, signs of infection, including intermittent diarrhea and pneumonia. In addition, as indicated by the increased frequency of infections, animals may be immunosuppressed and some animals also show growth retardation. These signs of persistent infection are particularly interesting because they have been postulated to be due to chronic IFN production to the persisting BVD virus [85, 87]. However, some PI animals may even be selected for breeding and give birth to calves that will also be PI,

\footnotetext{
$\overline{3}$ Bachofen C., BVD Virus in persistent infizierten Tieren: Bedeutung der intakten Haut als Infektionsquelle, Veterinary Doctoral thesis of the Vetsuisse Faculty, University of Bern, Switzerland, 2002.
}

indicating that infection may be innocuous in these animals.

After months or even years, the persistent infection may take a lethal course, characterized by bloody diarrhea, fever and in some cases, lesions in the mouth and interdigital clefts. In postmortem analysis, ulcera are found in different parts of the digestive tract, especially in the Peyer's patches. From animals suffering from this "mucosal disease", a cp BVD virus can be isolated in addition to the persisting ncp biotype. Since the ncp and cp BVDV strains isolated from an individual animal suffering from mucosal disease are antigenically and genetically very closely related, they are referred to as a "virus pair" [15]. Indeed, in PI animals, the $\mathrm{cp}$ biotype arises from its persisting ncp counterpart by genomic changes, e.g., point mutations or non-homologous RNA recombinations leading to the insertion of viral or cellular sequences (for reviews, see [45, 54, 63, 82]). The latter was shown to occur either by replicative template switching of the viral RNA-dependent RNA polymerase, or by viral replication-independent RNA recombination [29]. Genetic analysis of a large variety of BVD virus pairs revealed that the enhanced production of the nonstructural protein NS3 is the most important feature common to all $\mathrm{cp}$ strains characterized to date. The increase in NS3 synthesis correlates with the high rate of viral RNA synthesis and the induction of cell death by apoptosis in cell culture. Interestingly, cp field strains of BDV and CSFV, in contrast to BVDV, were rarely identified [63], and cp strains of CSFV were found to be cp DI particles that required the presence of an ncp CSFV helper virus ([30] and references therein). Such DI particles lacking most parts of the viral genome coding for the structural proteins, NS2 and p7, were similarly described in cp viruses isolated from cattle with mucosal disease [9].

One common modification of the BVDV genome to yield a cp biotype is the insertion of cellular gene fragments. For example, the insertions of ubiquitin- or ubiquitin-like genes occur rather frequently, which may or may not be accompanied by duplications of the viral genome including the NS3 region. Notably, the Osloss strain contains an insertion of a single 
ubiquitin gene at the N-terminus of NS3 without any duplication of viral sequences. Despite the fact that uncleaved NS2-3 is required for virus particle assembly [1, 67], this insertion within the NS2-3 gene of BVDV Osloss strain obviously does not impair the production of infectious virus particles.

Another type of recombination with cellular genes is the insertion of the Jiv ( $J$-domain protein interacting with viral protein) RNA or a fragment thereof (called Jiv90) in the NS2 $[80]$ or the $\mathrm{N}^{\text {pro }}$ region $[42,69]$ of the viral genome. Overexpression of this Jiv protein induces the cleavage of NS2-3 and thus leads to the appearance of a cytopathic effect in vitro. Intriguingly, the group of N. Tautz revealed that Jiv activates the autoprotease activity of NS2 in a stoichiometric amount [47, 49] and, importantly, that this autoprotease activity within NS2 is even essential for the replication of ncp BVDV [48]. Thus, NS3 is required for the replication of $\mathrm{BVDV}$, and cannot be replaced by uncleaved NS2-3. Due to the very limited amount of Jiv present in the host cell, NS2-3 cleavage in ncp BVDV-infected cells is temporally controlled and occurs to only a reduced extent (often only detectable at early time points post-infection), preventing the appearance of cytopathic effect. In ncp CSFV infections, NS3 expression can be observed also at later time points, but NS2-3 seems to be similarly controlled by the presence of cellular Jiv [30, 67], and Jiv overexpression strongly increases NS2-3 cleavage and leads to a cp biotype of CSFV [30].

Yet another type of genome modification found in $\mathrm{cp}$ biotypes consists of duplications and additional insertions of BVD viral sequences. Thus, various duplications of viral sequences including the NS3 region, insertion of the autoprotease $\mathrm{N}^{\text {pro }}$ upstream of NS3, or insertions into NS2 of sequences from the NS4B-NS5A-NS5B region of the genome ${ }^{4}$ [17] were described.

All these various RNA recombinations and mutations seem to make NS2-3 cleavage Jivindependent, thus uncoupling viral replication from the control by this essential host factor. This occurs by (i) activating the NS2 autopro-

\footnotetext{
$\overline{4}$ Antunes A., unpublished observation.
}

tease by supplying additional Jiv by the viral genome, (ii) inducing conformational changes within NS2 stimulating its activity in the absence of Jiv, or (iii) attracting other proteases of the host to excise NS3. The increased synthesis of NS3 then leads to enhanced viral RNA and protein production and to apoptosis.

The fact that BVD viruses of the cp biotype arise from ncp ones also explains a feature of mucosal disease that puzzled virologists when they were unsuccessfully trying to reproduce mucosal disease by inoculation of cp BVDV in immunologically naïve and BVDV-free animals. Thus, such animals readily mount an immune response to the $\mathrm{cp}$ virus, mostly without showing any sign of infection. In fact, many of the BVDV live vaccines are simply viral strains of the cp biotype [28, 32, 64]. In contrast to the control of infection with $\mathrm{cp} \mathrm{BVDV}$ in these animals, there is a continued uninhibited replication of the $\mathrm{cp}$ biotype emerging by mutation from its persisting and immunologically tolerated ncp counterpart, which explains the invariably fatal outcome of mucosal disease.

\section{EVOLUTION OF BVDV: THE ROLE OF PERSISTENT INFECTION AND THE EMERGENCE OF CP BIOTYPES}

Due to the high error rate and missing correction mechanism of the RNA-dependent RNA polymerase and, in the case of retroviruses such as human immunodeficiency virus (HIV), reverse transcriptase, RNA viruses display a high genetic plasticity, which is additionally increased by RNA recombination. As exemplified during persistent infection with HIV, the immune response favors the emergence of novel mutants that are capable of escaping the immune pressure exerted on the existing spectrum of viral variants. Over time, the continued emergence of new mutants changes the quasispecies present in the infected patient. An additional important element influencing viral evolution is viral transmission. In the case of HIV, it was estimated that approximately $80 \%$ of productive infections were the result of successful transmission of a single virus or a single virus-infected cell (reviewed 
in [101]). Due to repeated founder effects, the very limited spectrum of variants transmitted may further contribute to the rapid viral evolution observed within individual chains of infection. Compared to this scenario, the evolution of BVDV shows marked differences. As described above, PI animals are generated as a result of transient infection of pregnant cows, or are born to PI cows. We found a remarkable sequence conservation between PI animals and their PI calves, with the presence of a wide spectrum of variants that contrasts with the very narrow spectrum transmitted in HIV. The viral quasispecies did not markedly change over a period of one year in PI animals ${ }^{5}$. Furthermore, the nucleotide sequences of BVDV in PI animals living in the same herds were found to be very similar $([33,36,95]$, and unpublished observation). One obvious difference in the evolution of HIV versus BVDV is the different role the immune system plays in PI hosts. In contrast to HIV, BVDV is subject to immunotolerance during persistent infection, which is established early in gestation. This suggests that the immunotolerance may be specific for the BVD viral spectrum that was present during that period. The immune system may not only tolerate the original quasispecies of viruses, but in fact may prevent the emergence of antigenic variants that are outside of this spectrum. HIV and BVDV also differ in important aspects of transmission to new hosts. Thus, humans infected with HIV may travel the world and transmit virus to multiple partners, which increases the spread of virus to geographically distant regions. In contrast, most bovines live in individual, separate herds. The frequency of contact with animals of other herds depends mostly on management procedures. We observed an interesting example of this when we analyzed BVD viruses present in the Swiss cattle population. The different subgroups of BVDV type-1 (Fig. 3) showed a geographically randomized distribution in the entire cattle population, with no evidence of emergence or exclusion of any given subgroup of BVDV [5]. This correlated with the management practice of annual transhumance in the Alps of about

\footnotetext{
${ }^{5}$ Manuscript in preparation.
}

one third of the entire cattle population. According to old traditions, heifers originating from different herds and regions are kept in large herds during the summer months. In this age group of animals, herd immunity is lower than average, with many of the animals early in their first gestation and susceptible to infection. Before the start of the current Swiss BVDV eradication program there was no screening of animals for BVDV status before the summer grazing period. This was a significant risk factor for acute infection of heifers with BVDV and persistent infection in their offspring born in the following winter and early spring [13, 44, $81,86]$. The emergence and rapid spread of highly virulent BVDV type-2 strains during the late 1980s and early 1990s in Canada and the USA differ markedly from this stable endemic pattern found in Switzerland. Most likely, these strains could spread widely because herd immunity against BVDV type- 2 was low or absent, with no cross-protection by immunity to BVDV type-1 [74]. Similarly, various national and regional eradication programs without the use of vaccination were successfully implemented in Europe [53]. However, this will lead to antibody-negative, highly susceptible cattle populations, and strict biosecurity measures will be required to prevent that BVDV will become a "re-emerging" virus in these countries.

In contrast to the stable situation seen with the ncp biotype in a country where BVDV type- 1 is endemic and BVDV type- 2 is absent as described above, cp BVD viruses may indeed be viewed as "emerging", not least because these viruses pop up with a spectacular disease with a lethal outcome. Importantly, BVD viruses of this biotype, however, do not cause persistent infection, which would be required to maintain the virus in the host population, nor do they spread in the population to any significant extent. A very limited spread may occasionally be observed when additional animals persistently infected with a homologous virus strain succumb to mucosal disease in a herd due to superinfection by the $\mathrm{cp}$ virus shed by the index case of mucosal disease. However, the overall prevalence of PI animals is approximately $1 \%$ only, and clustering of 
PI animals in individual herds is limited. Hence, cp BVD viruses may be labeled as "emerging viruses doomed to extinction whenever they appear". In support of this interpretation, genetic analysis showed that the mutations leading to the $\mathrm{cp}$ biotype are unique in every $\mathrm{cp}$ BVD virus analyzed to date $[9,45,82]$.

BVD viruses of the $\mathrm{cp}$ biotype may be viewed as indicators of the genetic plasticity typical of RNA viruses in general. However, since there is no evidence to suggest that BVDV may differ in their genetic plasticity from other RNA viruses, the emergence of $\mathrm{cp}$ biotypes of BVDV causing mucosal disease may indeed be a very insensitive indicator indeed. Thus, on the one hand, the average age at which PI animals spontaneously develop mucosal disease is 6-18 or 24 months [14, 16, 26, 92], which corresponds well with the fact that mucosal lesions are mainly detected in older animals [6]. On the other hand, PI animals experimentally infected with homologous cp BVDV were shown to develop mucosal disease within a few weeks post-infection [27, 59]. Assuming that a PI animal may generate $10^{11}$ to $10^{12}$ virions per day [50] and that only 1 to $10 \%$ will be incorporated into infectious virus particles, it can be estimated that some $10^{14}-10^{17}$ viral genome copies may be required before a cp biotype capable of inducing mucosal disease may emerge. The apparent low frequency of the emergence of successful $\mathrm{cp}$ BVD viruses (i.e. capable of causing mucosal disease) can be explained by the numerous functional constraints these viruses must overcome. Among those are the requirements to be of the cp biotype, immunologically tolerated and of high fitness resulting in a buildup in numbers that explains the widespread destruction of lymphoid tissue that is typical of mucosal disease.

\section{CONCLUSION}

Mucosal disease is a rare example that signals viral evolution associated with a change of biotype leading to the death of the affected animal and, ultimately, also to the extinction of the $\mathrm{cp}$ virus that caused the fatal disease. Hence, the emergence of cp BVD viruses in
PI animals reflects an accident that remains without consequences for viral evolution. The paradoxical discrepancy between the apparent genetic stability of ncp BVDV, on the one hand, and the dramatic emergence of $\mathrm{cp}$ biotype viruses, on the other hand, can both be explained by immunotolerance. Thus, immunotolerance adds the ncp BVD virus to the "self repertoire" of its host early in embryogenesis. Continued immunotolerance may prevent the appearance of antigenic variants that might violate this tolerance over several generations of PI animals. This may be an important aspect of the preservation of individual viral strains in the cattle population, and implies that the large variety of BVDV strains observed today evolved over a long period of time. In contrast, the unrestricted multiplication of the $\mathrm{cp}$ biotype in PI animals may only be possible because the cp BVD virus is derived from the parental persisting ncp strain and thus is immunologically tolerated. As a unique aspect among all persistent viral infections known to date, the immune system may thus both preserve the virus and simultaneously enable the same virus to kill its host after it has undergone mutations that result in the loss of its ability to replicate in its host cells without triggering apoptosis.

Acknowledgements. In the recent years, this work was supported by the Swiss National Science Foundation, grant No. 3100A0-109597 (to E. Peterhans) and 3200-068305 (to M. Schweizer). We are grateful to Michael Wegmüller for designing Figure 1, and we thank Ruth Parham for her linguistic improvement of the manuscript.

\section{REFERENCES}

[1] Agapov E.V., Murray C.L., Frolov I., Qu L., Myers T.M., Rice C.M., Uncleaved NS2-3 is required for production of infectious bovine viral diarrhea virus, J. Virol. (2004) 78:2414-2425.

[2] Anonymous, Hepatitis C - global prevalence, Wkly Epidemiol. Rec. (1999) 74:421-428.

[3] Arnal M.C., Fernández-De-Luco D., Riba L., Maley M., Gilray J., Willoughby K., et al., A novel pestivirus associated with deaths in Pyrenean chamois (Rupicapra pyrenaica pyrenaica), J. Gen. Virol. (2004) 85:3653-3657. 
[4] Audet S.A., Crim R.L., Beeler J., Evaluation of vaccines, interferons and cell substrates for pestivirus contamination, Biologicals (2000) 28:41-46.

[5] Bachofen C., Stalder H., Braun U., Hilbe M., Ehrensperger F., Peterhans E., Co-existence of genetically and antigenically diverse bovine viral diarrhoea viruses in an endemic situation, Vet. Microbiol. (2008) 131:93-102.

[6] Bachofen C., Braun U., Hilbe M., Ehrensperger F., Stalder H.P., Peterhans E., Clinical appearance and pathology of cattle persistently infected with bovine viral diarrhoea virus of different genetic subgroups, Vet. Microbiol. (2010) 141:258-267.

[7] Balint A., Baule C., Pálfi V., Belák S., Retrospective genome analysis of a live vaccine strain of bovine viral diarrhea virus, Vet. Res. (2005) 36:89-99.

[8] Bauhofer O., Summerfield A., Sakoda Y., Tratschin J.D., Hofmann M.A., Ruggli N., Classical swine fever virus $\mathrm{N}^{\text {pro }}$ interacts with interferon regulatory factor 3 and induces its proteasomal degradation, J. Virol. (2007) 81:3087-3096.

[9] Becher P., Orlich M., König M., Thiel H.-J., Nonhomologous RNA recombination in bovine viral diarrhea virus: molecular characterization of a variety of subgenomic RNAs isolated during an outbreak of fatal mucosal disease, J. Virol. (1999) 73: 5646-5653.

[10] Becher P., Avalos-Ramirez R., Orlich M., Rosales S.C., König M., Schweizer M., et al., Genetic and antigenic characterization of novel pestivirus genotypes: implications for classification, Virology (2003) 311:96-104.

[11] Bonjardim C.A., Interferons (IFNs) are key cytokines in both innate and adaptive antiviral immune responses - and viruses counteract IFN action, Microbes Infect. (2005) 7:569-578.

[12] Brackenbury L.S., Carr B.V., Charleston B., Aspects of the innate and adaptive immune responses to acute infections with BVDV, Vet. Microbiol. (2003) 96:337-344.

[13] Braun U., Schönmann M., Ehrensperger F., Hilbe M., Brunner D., Stark K.D.C., Giger T., Epidemiology of bovine virus diarrhoea in cattle on communal alpine pastures in Switzerland, J. Vet. Med. A Physiol. Pathol. Clin. Med. (1998) 45:445-452.

[14] Brownlie J., Clarke M.C., Howard C.J., Pocock D.H., Pathogenesis and epidemiology of bovine virus diarrhoea virus infection of cattle, Ann. Rech. Vet. (1987) 18:157-166.

[15] Brownlie J., Pathogenesis of mucosal disease and molecular aspects of bovine virus diarrhoea virus, Vet. Microbiol. (1990) 23:371-382.
[16] Brownlie J., The pathways for bovine virus diarrhoea virus biotypes in the pathogenesis of disease, Arch. Virol. Suppl. (1991) 3:79-96.

[17] Bálint A., Pálfi V., Belák S., Baule C., Viral sequence insertions and a novel cellular insertion in the NS2 gene of cytopathic isolates of bovine viral diarrhea virus as potential cytopathogenicity markers, Virus Genes (2005) 30:49-58.

[18] Charleston B., Fray M.D., Baigent S., Carr B.V., Morrison W.I., Establishment of persistent infection with non-cytopathic bovine viral diarrhoea virus in cattle is associated with a failure to induce type I interferon, J. Gen. Virol. (2001) 82:1893-1897.

[19] Charleston B., Brackenbury L.S., Carr B.V., Fray M.D., Hope J.C., Howard C.J., Morrison W.I., Alpha/ beta and gamma interferons are induced by infection with noncytopathic bovine viral diarrhea virus in vivo, J. Virol. (2002) 76:923-927.

[20] Chase C.C.L., Elmowalid G., Yousif A.A.A., The immune response to bovine viral diarrhea virus: a constantly changing picture, Vet. Clin. North Am. Food Anim. Pract. (2004) 20:95-114.

[21] Chisari F.V., Unscrambling hepatitis C virus-host interactions, Nature (2005) 436:930-932.

[22] Cleaveland S., Haydon D.T., Taylor L., Overviews of pathogen emergence: which pathogens emerge, when and why?, Curr. Top. Microbiol. Immunol. (2007) 315:85-111.

[23] Dubois E., Russo P., Prigent M., Thiéry R., Genetic characterization of ovine pestiviruses isolated in France, between 1985 and 2006, Vet. Microbiol. (2008) 130:69-79.

[24] Finlaison D.S., King K.R., Frost M.J., Kirkland P.D., Field and laboratory evidence that Bungowannah virus, a recently recognised pestivirus, is the causative agent of the porcine myocarditis syndrome (PMC), Vet. Microbiol. (2009) 136:259-265.

[25] Fitzgerald-Bocarsly P., Feng D., The role of type I interferon production by dendritic cells in host defense, Biochimie (2007) 89:843-855.

[26] Fritzemeier J., Greiser-Wilke I., Haas L., Moennig V., New insights into the pathogenesis of mucosal disease (MD) of cattle, Prakt. Tierarzt (1997) 78:128-133.

[27] Fritzemeier J., Haas L., Liebler E.M., Moennig V., Greiser-Wilke I., The development of early vs. late onset mucosal disease is a consequence of two different pathogenic mechanisms, Arch. Virol. (1997) 142: 1335-1350.

[28] Fulton R.W., Ridpath J.F., Saliki J.T., Briggs R.E., Confer A.W., Burge L.J., et al., Bovine viral 
diarrhea virus (BVDV) 1b: predominant BVDV subtype in calves with respiratory disease, Can. J. Vet. Res. (2002) 66:181-190.

[29] Gallei A., Pankraz A., Thiel H.J., Becher P., RNA recombination in vivo in the absence of viral replication, J. Virol. (2004) 78:6271-6281.

[30] Gallei A., Blome S., Gilgenbach S., Tautz N., Moennig V., Becher P., Cytopathogenicity of classical swine fever virus correlates with attenuation in the natural host, J. Virol. (2008) 82:9717-9729.

[31] Gil L.H.V.G., Ansari I.H., Vassilev V., Liang D.L., Lai V.C.H., Zhong W.D., et al., The aminoterminal domain of bovine viral diarrhea virus $\mathrm{N}^{\text {pro }}$ protein is necessary for alpha/beta interferon antagonism, J. Virol. (2006) 80:900-911.

[32] Givens M.D., Riddell K.P., Zhang Y., Galik P., Walz P.H., Brodersen B.W., et al., Safety and efficacy of vaccination of seronegative bulls with modifiedlive, cytopathic bovine viral diarrhea viruses, Theriogenology (2009) 71:975-983.

[33] Hamers C., Lecomte C., Kulcsar G., Lambot M., Pastoret P.P., Persistently infected cattle stabilise bovine viral diarrhea virus leading to herd specific strains, Vet. Microbiol. (1998) 61:177-182.

[34] Hamers C., Dehan P., Couvreur B., Letellier C., Kerkhofs P., Pastoret P.P., Diversity among bovine pestiviruses, Vet. J. (2001) 161:112-122.

[35] Hilton L., Moganeradj K., Zhang G., Chen Y.H., Randall R.E., McCauley J.W., Goodbourn S., The NPro product of bovine viral diarrhea virus inhibits DNA binding by interferon regulatory factor 3 and targets it for proteasomal degradation, J. Virol. (2006) 80:11723-11732.

[36] Hornberg A., Fernández S.R., Vogl C., Vilcek S., Matt M., Fink M., et al., Genetic diversity of pestivirus isolates in cattle from Western Austria, Vet. Microbiol. (2009) 135:205-213.

[37] Houe H., Epidemiology of bovine viral diarrhea virus, Vet. Clin. North Am. Food Anim. Pract. (1995) 11:521-547.

[38] Iqbal M., Poole E., Goodbourn S., McCauley J.W., Role for bovine viral diarrhea virus $\mathrm{E}^{\mathrm{rns}}$ glycoprotein in the control of activation of beta interferon by doublestranded RNA, J. Virol. (2004) 78:136-145.

[39] Jackova A., Novackova M., Pelletier C., Audeval C., Gueneau E., Haffar A., et al., The extended genetic diversity of BVDV-1: typing of BVDV isolates from France, Vet. Res. Commun. (2008) 32:7-11.

[40] Jones K.E., Patel N.G., Levy M.A., Storeygard A., Balk D., Gittleman J.L., Daszak P., Global trends in emerging infectious diseases, Nature (2008) 451:990-993.
[41] Jones L.R., Cigliano M.M., Zandomeni R.O., Weber E.L., Phylogenetic analysis of bovine pestiviruses: testing the evolution of clinical symptoms, Cladistics (2004) 20:443-453.

[42] Kameyama K., Sakoda Y., Tamai K., Nagai M., Akashi H., Kida H., Genetic recombination at different points in the $\mathrm{N}^{\text {pro }}$-coding region of bovine viral diarrhea viruses and the potentials to change their antigenicities and pathogenicities, Virus Res. (2006) 116:78-84.

[43] Kirkland P.D., Frost M., Finlaison D.S., King K.R., Ridpath J.F., Gu X., Identification of a novel virus in pigs-Bungowannah virus: a possible new species of pestivirus, Virus Res. (2007) 129:26-34.

[44] Krametter-Frötscher R., Loitsch A., Kohler H., Schleiner A., Schiefer P., Möstl K., et al., Serological survey for antibodies against pestiviruses in sheep in Austria, Vet. Rec. (2007) 160:726-730.

[45] Kümmerer B.M., Tautz N., Becher P., Thiel H.J., Meyers G., The genetic basis for cytopathogenicity of pestiviruses, Vet. Microbiol. (2000) 77:117-128.

[46] La Rocca S.A., Herbert R.J., Crooke H., Drew T.W., Wileman T.E., Powell P.P., Loss of interferon regulatory factor 3 in cells infected with classical swine fever virus involves the N-terminal protease, $\mathrm{N}^{\text {pro }}$, J. Virol. (2005) 79:7239-7247.

[47] Lackner T., Müller A., Pankraz A., Becher P., Thiel H.J., Gorbalenya A.E., Tautz N., Temporal modulation of an autoprotease is crucial for replication and pathogenicity of an RNA virus, J. Virol. (2004) 78:10765-10775.

[48] Lackner T., Müller A., König M., Thiel H.J., Tautz N., Persistence of bovine viral diarrhea virus is determined by a cellular cofactor of a viral autoprotease, J. Virol. (2005) 79:9746-9755.

[49] Lackner T., Thiel H.J., Tautz N., Dissection of a viral autoprotease elucidates a function of a cellular chaperone in proteolysis, Proc. Natl. Acad. Sci. USA (2006) 103:1510-1515.

[50] Layden T.J., Mika B., Wiley T.E., Hepatitis C kinetics: mathematical modeling of viral response to therapy, Semin. Liver Dis. (2000) 20:173-183.

[51] Le Bon A., Tough D.F., Type I interferon as a stimulus for cross-priming, Cytokine Growth Factor Rev. (2008) 19:33-40.

[52] Lee H.K., Iwasaki A., Innate control of adaptive immunity: dendritic cells and beyond, Semin. Immunol. (2007) 19:48-55.

[53] Lindberg A., Brownlie J., Gunn G.J., Houe H., Moennig V., Saatkamp H.W., et al., The control of bovine viral diarrhoea virus in Europe: today and in the future, Rev. Sci. Tech. (2006) 25:961-979. 
[54] Lindenbach B.D., Thiel H.-J., Rice C.M., Flaviviridae: the viruses and their replication, in: Knipe D.M., Howley P.M. (Eds.), Fields Virology, 5th ed., Lippincott-Raven Publishers, Philadelphia, 2007, pp. 1101-1152.

[55] Liu L., Kampa J., Belák S., Baule C., Virus recovery and full-length sequence analysis of atypical bovine pestivirus Th/04 KhonKaen, Vet. Microbiol. (2009) 138:62-68.

[56] Liu L., Xia H., Baule C., Belák S., Maximum likelihood and Bayesian analyses of a combined nucleotide sequence dataset for genetic characterization of a novel pestivirus, SVA/cont-08, Arch. Virol. (2009) 154:1111-1116.

[57] Liu L., Xia H., Wahlberg N., Belák S., Baule C., Phylogeny, classification and evolutionary insights into pestiviruses, Virology (2009) 385:351-357.

[58] Liu L., Xia H., Baule C., Belák S., Wahlberg N., Effects of methodology and analysis strategy on robustness of pestivirus phylogeny, Virus Res. (2010) 147:47-52.

[59] Loehr B.I., Frey H.R., Moennig V., GreiserWilke I., Experimental induction of mucosal disease: consequences of superinfection of persistently infected cattle with different strains of cytopathogenic bovine viral diarrhea virus, Arch. Virol. (1998) 143:667-679.

[60] Magkouras I., Mätzener P., Rümenapf T., Peterhans E., Schweizer M., RNase-dependent inhibition of extra-, but not intracellular, dsRNA-induced IFN synthesis by $E^{\text {rns }}$ of pestiviruses, J. Gen. Virol. (2008) 89:2501-2506.

[61] Marco I., Rosell R., Cabezón O., Mentaberre G., Casas E., Velarde R., et al., Epidemiological study of border disease virus infection in Southern chamois (Rupicapra pyrenaica) after an outbreak of disease in the Pyrenees (NE Spain), Vet. Microbiol. (2008) 127:29-38.

[62] Merten O.W., Virus contaminations of cell cultures - a biotechnological view, Cytotechnology (2002) 39:91-116.

[63] Meyers G., Thiel H.-J., Molecular characterization of pestiviruses, Adv. Virus Res. (1996) 47:53-118.

[64] Moennig V., Plagemann P.G.W., The pestiviruses, Adv. Virus Res. (1992) 41:53-98.

[65] Mogensen T.H., Pathogen recognition and inflammatory signaling in innate immune defenses, Clin. Microbiol. Rev. (2009) 22:240-273.

[66] Morens D.M., Folkers G.K., Fauci A.S., The challenge of emerging and re-emerging infectious diseases, Nature (2004) 430:242-249.

[67] Moulin H.R., Seuberlich T., Bauhofer O., Bennett L.C., Tratschin J.D., Hofmann M.A., Ruggli N.,
Nonstructural proteins NS2-3 and NS4A of classical swine fever virus: essential features for infectious particle formation, Virology (2007) 365: 376-389.

[68] Mätzener P., Magkouras I., Rümenapf T., Peterhans E., Schweizer M., The viral RNase $E^{\text {rns }}$ prevents IFN type-I triggering by pestiviral single- and double-stranded RNAs, Virus Res. (2009) 140:15-23.

[69] Müller A., Rinck G., Thiel H.J., Tautz N., Cellderived sequences in the $\mathrm{N}$-terminal region of the polyprotein of a cytopathogenic pestivirus, J. Virol. (2003) 77:10663-10669.

[70] Nagai M., Hayashi M., Itou M., Fukutomi T., Akashi H., Kida H., Sakoda Y., Identification of new genetic subtypes of bovine viral diarrhea virus genotype 1 isolated in Japan, Virus Genes (2008) 36:135-139.

[71] Oguzoglu T.C., Tan M.T., Toplu N., Demir A.B., Bilge-Dagalp S., Karaoglu T., et al., Border disease virus (BDV) infections of small ruminants in Turkey: a new BDV subgroup?, Vet. Microbiol. (2009) 135: 374-379.

[72] Olafson P., MacCallum A.D., Fox F.H., An apparently new transmissible disease of cattle, Cornell Vet. (1946) 36:205-213.

[73] Palm N.W., Medzhitov R., Not so fast: adaptive suppression of innate immunity, Nat. Med. (2007) 13:1142-1144.

[74] Pellerin C., van den Hurk J., Lecomte J., Tussen P., Identification of a new group of bovine viral diarrhea virus strains associated with severe outbreaks and high mortalities, Virology (1994) 203:260-268.

[75] Peterhans E., Jungi T.W., Schweizer M., BVDV and innate immunity, Biologicals (2003) 31:107-111.

[76] Peterhans E., Jungi T.W., Schweizer M., How the bovine viral diarrhea virus outwits the immune system, Dtsch. Tierarztl. Wochenschr. (2006) 113: 124-129.

[77] Peterhans E., Schweizer M., Pestiviruses: how to outmaneuver your hosts, Vet. Microbiol. (2010) 142:18-25.

[78] Pioz M., Loison A., Gibert P., Dubray D., Menaut P., Le Tallec B., et al., Transmission of a pestivirus infection in a population of Pyrenean chamois, Vet. Microbiol. (2007) 119:19-30.

[79] Potgieter L.N., Immunology of bovine viral diarrhea virus, Vet. Clin. North Am. Food Anim. Pract. (1995) 11:501-520.

[80] Rinck G., Birghan C., Harada T., Meyers G., Thiel H.J., Tautz N., A cellular J-domain protein modulates polyprotein processing and cytopathogenicity of a pestivirus, J. Virol. (2001) 75:9470-9482. 
[81] Rüfenacht J., Schaller P., Audigé L., Strasser M., Peterhans E., Prevalence of cattle infected with bovine viral diarrhoea virus in Switzerland, Vet. Rec. (2000) $147: 413-417$.

[82] Rümenapf T., Thiel H.-J., Molecular biology of pestiviruses, in: Mettenleiter T.C., Sobrino F. (Eds.), Animal viruses: molecular biology, Caister Academic Press, Norwich, UK, 2008, pp. 39-96.

[83] Schirrmeier H., Strebelow G., Depner K., Hoffmann B., Beer M., Genetic and antigenic characterization of an atypical pestivirus isolate, a putative member of a novel pestivirus species, J. Gen. Virol. (2004) 85:3647-3652.

[84] Shepard C.W., Finelli L., Alter M., Global epidemiology of hepatitis $\mathrm{C}$ virus infection, Lancet Infect. Dis. (2005) 5:558-567.

[85] Shoemaker M.L., Smirnova N.P., BielefeldtOhmann H., Austin K.J., Van Olphen A., Clapper J.A., Hansen T.R., Differential expression of the type I interferon pathway during persistent and transient bovine viral diarrhea virus infection, J. Interferon Cytokine Res. (2009) 29:23-35.

[86] Siegwart N., Hilbe M., Hässig M., Braun U., Increased risk of BVDV infection of calves from pregnant dams on communal alpine pastures in Switzerland, Vet. J. (2006) 172:386-388.

[87] Smirnova N.P., Bielefeldt-Ohmann H., Van Campen H., Austin K.J., Han H., Montgomery D.L., et al., Acute non-cytopathic bovine viral diarrhea virus infection induces pronounced type I interferon response in pregnant cows and fetuses, Virus Res. (2008) 132:49-58.

[88] Snowden F.M., Emerging and reemerging diseases: a historical perspective, Immunol. Rev. (2008) 225:9-26.

[89] Ståhl K., Kampa J., Alenius S., Wadman A.P., Baule C., Aiumlamai S., Belák S., Natural infection of cattle with an atypical 'HoBi'-like pestivirus - implications for BVD control and for the safety of biological products, Vet. Res. (2007) 38:517-523.

[90] Stalder H.P., Meier P., Pfaffen G., Wageck-Canal C., Rüfenacht J., Schaller P., et al., Genetic heterogeneity of pestiviruses of ruminants in Switzerland, Prev. Vet. Med. (2005) 72:37-41.

[91] Steinman R.M., Hemmi H., Dendritic cells: translating innate to adaptive immunity, in: From innate immunity to immunological memory, SpringerVerlag, Berlin, 2006, pp. 17-58.

[92] Tautz N., Meyers G., Thiel H.J., Pathogenesis of mucosal disease, a deadly disease of cattle caused by a pestivirus, Clin. Diagn. Virol. (1998) 10:121-127.
[93] Valdazo-González B., Álvarez-Martínez M., Greiser-Wilke I., Genetic typing and prevalence of border disease virus (BDV) in small ruminant flocks in Spain, Vet. Microbiol. (2006) 117:141-153.

[94] Valdazo-González B., Álvarez-Martínez M., Sandvik T., Genetic and antigenic typing of border disease virus isolates in sheep from the Iberian Peninsula, Vet. J. (2007) 174:316-324.

[95] Vilček Š., Alenius S., Paton D.J., Mittelholzer C., Belák S., Genetic clustering of bovine viral diarrhoea viruses in cattle farms: genetic identification and analysis of viruses directly from cattle sera, Vet. J. (1999) 158:33-38.

[96] Vilček Š., Identification of pestiviruses contaminating cell lines and fetal calf sera, Acta Virol. (2001) 45:81-86.

[97] Vilček Š., Paton D.J., Durkovič B., Strojny L., Ibata G., Moussa A., et al., Bovine viral diarrhoea virus genotype 1 can be separated into at least eleven genetic groups, Arch. Virol. (2001) 146:99-115.

[98] Vilček Š., Ďurkovič B., Kolesárová M., GreiserWilke I., Paton D., Genetic diversity of international bovine viral diarrhoea virus (BVDV) isolates: identification of a new BVDV-1 genetic group, Vet. Res. (2004) 35:609-615.

[99] Vilček S., Nettleton P.F., Pestiviruses in wild animals, Vet. Microbiol. (2006) 116:1-12.

[100] Vivier E., Malissen B., Innate and adaptive immunity: specificities and signaling hierarchies revisited, Nat. Immunol. (2005) 6:17-21.

[101] Woodman Z., Williamson C., HIV molecular epidemiology: transmission and adaptation to human populations, Curr. Opin. HIV AIDS (2009) 4:247-252.

[102] Xu X.R., Zhang Q.C., Yu X.L., Liang L., Xiao C., Xiang H., Tu C.C., Sequencing and comparative analysis of a pig bovine viral diarrhea virus genome, Virus Res. (2006) 122:164-170.

[103] Yamane D., Kato K., Tohya Y., Akashi H., The double-stranded RNA-induced apoptosis pathway is involved in the cytopathogenicity of cytopathogenic bovine viral diarrhea virus, J. Gen. Virol. (2006) 87:2961-2970.

[104] Yeşilbağ K., Förster C., Bank-Wolf B., Yilmaz Z., Alkan F., Ozkul A., et al., Genetic heterogeneity of bovine viral diarrhoea virus (BVDV) isolates from Turkey: identification of a new subgroup in BVDV-1, Vet. Microbiol. (2008) 130:258-267.

[105] Zhao J., Yang X.M., Auh S.L., Kim K.D., Tang H., $\mathrm{Fu}$ Y.X., Do adaptive immune cells suppress or activate innate immunity?, Trends Immunol. (2009) 30:8-12. 